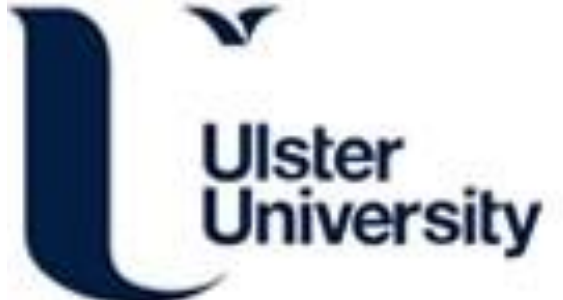

\section{Exploratory Factor Analysis of the Caregiver Grief Inventory in a Large UK Sample of Dementia Carers}

Gilsenan, J., Gorman, C., \& Shevlin, M. (2020). Exploratory Factor Analysis of the Caregiver Grief Inventory in a Large UK Sample of Dementia Carers. Aging and Mental Health, 26(2), 320-327. https://doi.org/10.1080/13607863.2020.1839856

Link to publication record in Ulster University Research Portal

Published in:

Aging and Mental Health

Publication Status:

Published online: 05/11/2020

DOI:

10.1080/13607863.2020.1839856

Document Version

Author Accepted version

\section{General rights}

Copyright for the publications made accessible via Ulster University's Research Portal is retained by the author(s) and / or other copyright owners and it is a condition of accessing these publications that users recognise and abide by the legal requirements associated with these rights.

\section{Take down policy}

The Research Portal is Ulster University's institutional repository that provides access to Ulster's research outputs. Every effort has been made to ensure that content in the Research Portal does not infringe any person's rights, or applicable UK laws. If you discover content in the Research Portal that you believe breaches copyright or violates any law, please contact pure-support@ulster.ac.uk. 


\title{
Exploratory Factor Analysis of the Caregiver Grief Inventory in a Large UK Sample of Dementia Carers
}

\author{
Jane Gilsenan $^{1}$ \\ Colin Gorman ${ }^{1 *}$ \\ Mark Shevlin ${ }^{1}$
}

${ }^{1}$ School of Psychology, Ulster University

*Address correspondence to: Dr Colin Gorman, Department of Psychology, Ulster University, Cromore Road, Coleraine BT52 1SA. Email: c.gorman@ulster.ac.uk. 


\title{
Exploratory Factor Analysis of the Caregiver Grief Inventory in a Large UK Sample of Dementia Carers
}

\begin{abstract}
Objectives: Anticipatory grief (AG) is the process of experiencing loss prior to the death of a significant person. Coping with this multifaceted experience in the context of dementia caregiving is a relatively novel, yet significant area in caregiving literature. The MarwitMeuser Caregiver Grief Inventory (MM-CGI) and its abbreviated MM-CGI-Short-Form (MM-CGI-SF) is the most widely used scale measuring AG. However, limited research has employed robust analytical strategies to assess its dimensional structure. This study employed contemporary factor analytical techniques to assess the dimensional structure of the MM-CGI / SF.
\end{abstract}

Method: Caregivers of persons with dementia $(n=508)$ completed a survey containing MMCGI / SF and other associated psychological measures. Exploratory factor analysis was employed to compare eight alternative factor analytical models to determine the optimal model. Internal-consistency reliability was assessed by Cronbach's $\alpha$ and construct validity was assessed by Spearman's correlation-coefficient.

Results: The best fitting model was the MM-CGI-SF three factor model (Personal Sacrifice and Burden, Heartfelt Sadness and Longing and Worry and Felt Isolation). The MM-CGI-SF three factor model demonstrated internal consistency reliability and factor correlations with associated psychological measures indicated construct validity.

Conclusion: The MM-CGI-SF three factor model demonstrated adequate fit and utility, however, the Worry and Felt Isolation subscale needs further replication and revision to assess its dimensionality. The MM-CGI-SF is the more useful tool due to its brevity and better model fit. 
Keywords: Anticipatory Grief, Contemporary Analytic Techniques, Burden, Family Members. 


\section{Introduction}

Grief is a universal, psychologically complex experience involving a response to a significant loss. It is idiosyncratic and multifaceted in nature, and perhaps will never be fully understood by researchers, professionals and society alike. Prominent grief theories suggest that one aspect of loss is that it can have a profound effect on an individual's psychological functioning, resulting in a period of time where the individual suffers intense grief for the loss of their loved one to the degree that this emotional state impacts upon general functioning (Stroebe \& Schütt, 1999). While the memory of the individual does not necessarily dissipate, the 'grief' can begin to subside as time proceeds, and most people gradually arrive at an emotional equilibrium following their loss (Jordan \& Litz, 2014). For others, their grief experience can become increasingly disabling and distressing, causing prolonged symptoms which inhibit life adjustment (Boelen, Lenferink \& Smid, 2019). These symptoms are now recognised under Persistent Complex Grief Disorder (PCBCD) in the DSM-5 (APA, 2013) and Prolonged Grief Disorder (PGD) in the ICD-11 (WHO, 2018).

While grief is a part of common language and universal in nature it is a relatively novel construct in dementia caregiving literature despite its undoubted relevance. Approximately 700,000 family and friends are dementia carers in the UK (Alzheimer's Research UK, 2015). These family members provide a wide range of care and support ranging from the most basic of assistance to full responsibility for all personal needs. They are fundamental to the quality of life of care-recipients and essential to the fabric of our society in an aging population. Their value is supported by the NICE-recommended dementia care pathway, which endorses offering caregiver assessments and intervention/s for their emotional, psychological and social needs (National Collaborating Centre for Mental Health, 2018; NICE, 2018). 
Beyond more general mental health and emotional needs of which many dementia caregivers suffer, the 'natural' process of grieving for a loved one with dementia can create a relatively unique and emotionally complex situation. When an individual with dementia gradually recedes from their loved one through being progressively altered in terms of characteristics that made them inimitably them, the sadness is profound (Blandin \& Pepin, 2017; Frank, 2008). Caregivers have no control over rates of change and therefore have no choice but to witness multiple, incremental and unexpected losses through cumulative changes in personality, cognitive and physical capabilities. Currently, the dementia journey only ends with the death of the person. Consequently, dementia is often described as 'dual dying' (Jones \& Martinson, 1992), with 'multiple losses' experienced first as the disease progresses and 'takes away' the known person, both personally, physically and cognitively (Holley \& Mast, 2009; Lindauer \& Harvath, 2014), and secondly, when physical death ultimately occurs. This first stage is primarily described as "Anticipatory Grief" (AG) in dementia caregiving literature; as well as "Pre-death Grief" (Lindauer \& Harvath, 2014), “Caregiver Grief” (Large \& Slinger, 2015) and "Dementia Grief” (Blandin \& Pepin, 2017). Each term relates to an attempt to describe the experience involving the 'ambiguous' losses accompanying the trajectory of decline dementia involves (Boss, 1999; 2011). Ultimately, they refer to the process of experiencing the phases of grief in advance of the death of a significant person (Rando, 1986; 2000). While there has been no clear consensus on the definition of AG it has been described as both "multifaceted" and "inescapable", starting early in the process and continuing throughout (Lord, 2010).

In order to understand the emotional dimensions and ultimately the process associated with AG, it is important to understand the underlying latent structure of the scales which aim to measure it. The most widely used scale employed to assess grief in dementia caregiving literature is Marwit and Meuser's (2001; 2002; 2004; 2005) caregiver grief inventory (MM- 
CGI / SF). This measure aims to assess a full range of affective responses to the loss of the care-recipient, including cognitive, behavioural and emotional losses. It was initially developed in the United States using an extensive focus group approach with 89 primary caregivers of relatives with dementia; resulting in the generation of 184 grief related items from 16 focus group transcriptions. These items were then administrated to a different group of 166 primary caregivers, which resulted in identifying a 50-item scale by principal axis factor analysis with oblique rotation. Three primary dimensions of loss were identified; Personal Sacrifice and Burden, Heartfelt Sadness and Longing and Worry and Felt Isolation. "Personal Sacrifice and Burden" essentially reflects the broader dimensions of grief, thus capturing the personal elements of the caregiver's life which have been affected due to their caregiving role - such as their sleep, physical health and personal freedom. "Heartfelt Sadness and Longing" captures intrapersonal reactions, including personal sadness and separation pain associated with loss and grief. "Worry and Felt Isolation" represents feelings of uncertainty, isolation \& withdrawal associated with losing connection with others and the worry about future losses.

The Marwit-Meuser Caregiver Grief Inventory-Short Form (MM-CGI-SF) evolved from further statistical analysis, which consists of the 3 -factor model with the 18 most representative items (Marwit \& Meuser, 2005). Several studies have used the MM-CGI and MM-CGI-SF to examine patterns of AG, as well its relationship to other psychological constructs such as caregiver perceived burden and stress (Marwit \& Meuser, 2005; Holly \& Mast, 2009; Liew et al., 2018). Validity and utility of the measure has also been explored in different populations (Alvelo, Cancio-Gonzalez \& Andre's Collazo, 2016; Chan, Wong, Kwok, \& Ho, 2017; Liew et al., 2017; McLennon, Bakas, Haberman, and Meuser, 2014). However, only two of these validation studies factor analysed the scale to assess its dimensional structure (Alvelo et al., 2016; Liew et al., 2018). Further, item-scores for the 
short form were not factor analysed by the authors (Marwit \& Meuser, 2005), validity was confirmed by corelating subscale scores to additional measures that were expected to be theoretically related; such as the Beck Depression Inventory (BDI; Beck et al., 1961) and the Caregiver Strain Index (Sullivan, 2002).

Alvelo et al's., (2016) factor analytic findings with 100 Spanish caregivers failed to replicate the three-factor structure. Using exploratory factor analysis, their findings supported a one-factor structure underlying the scale. By contrast, Liewet al (2018) examined the validity and utility of the MM-CGI and MM-CGI-SF with a larger sample of dementia caregivers $(n=300)$ from a multi-ethnic Asian population. They employed a more extensive analysis by comparing the model fit between a 3-factor model and 1-factor model; and between MM-CGI and MM-CGI-SF. Factor analytic results indicated that the three-factor MM-CGI-SF had the best model fit. The items for the Personal Sacrifice and Burden and Heartfelt Sadness and Longing dimensions loaded on their original factors, however, the Worry and Felt Isolation dimension was less well defined: items cross loaded onto the Heartfelt Sadness and Longing dimension. Overall, they concluded that MM-CGI-SF three factor model is the better measure giving its model fit and shorter administration time.

Limited research has employed contemporary factor analytic techniques to assess the dimensionality of the MMCGI / SF. It is important to determine the optimal factor structure as this determines how the scale should be scored; should it be a unidimensional grief scale, or should a number of subscales be used to reflect the multi-dimensional nature of AG? This study adds to the extant research literature as it (1) employed the largest sample of dementia caregivers of any factor analytic study of the MM-CGI / SF, (2) used contemporary factor analytic methods that employ robust methods of estimation and objective, statistically based, criteria to determine the optimal model, (3) analysed and compared both the original 50-items 
scale and the 16-item abbreviated version, and (4) assessed the concurrent validity of the factors derived from the factor analysis using a range of associated psychological variables.

\section{Methods}

\section{Participants}

Participants were 508 caregivers of persons with dementia in the United Kingdom. Caregivers were recruited primarily through Join Dementia Research - a dementia research register in the UK, as well as Young Dementia UK and online support groups. Eligibility for inclusion required that the caregiver be over the age of 18 , a family member or close loved one of an adult with dementia, who at the time of participation in the study provided some level of care and support to the care recipient. Demographic characteristics of the participants and the caregiving situation are presented in Table 1 . The mean age of caregivers was 54 years, the majority were female (86.6\%), white/white British (96.5\%), who cared for a parent $(49.9 \%)$ or spouse $(23.7 \%)$ with dementia. On average, caregivers had been providing care for 1-3 years, and caregivers most commonly reported that the care recipients had moved from independent living to living with family and/or receiving home care (66.4\%). Caregivers most commonly reported providing care a few times a week (27.8\%) or full-time care $(35.2 \%)$.

\section{Insert Table 1 Here}

\section{Procedure}

The study took the form of an online survey which was created using Qualtrics software. The inclusion criteria were screened for in the Join Dementia Research (JDR) register to identify potentially eligible participants. Matched volunteers on JDR, who were 
deemed to have met the research inclusion criteria, were forwarded information via email from JDR and the researchers about the nature of the study and potential participation. Participants who were recruited from Young Dementia UK and Online support dementia groups, contacted the researchers to discuss potential inclusion before survey completion. Informed consent was obtained from each participant and participants were provided with details pertinent to the study outlined on the information sheet. Participants were fully informed of their rights and all information about participants was treated as confidential and anonymous. Prior to data collection the study was granted ethical approval by Ulster Universities Research Ethics Committee.

\section{Measures}

\section{Demographic Survey}

Information was obtained on a range of socio-demographic variables for the caregiver and care recipient; including the caregivers age, gender, ethnicity, duration of caregiving, frequency of caregiving and level of additional support. The care recipients living arrangements and the caregiver's relationship to the care recipient were also measured.

Caregiver Anticipatory Grief - The Marwit-Meuser Caregiver Grief Inventory MM-CGI \& $M M-C G I-S F$.

The MM-CGI (50-item) and MM-CGI-SF (18-item) were employed as our primary variables. Both the MM-CGI and MM-CGI-SF are comprised of three subscales; (a) Personal Sacrifice and Burden (MM-CGI 18 items / MM-CGI-SF 6 item), (b) Heartfelt Sadness and Longing 
(MM-CGI 15 items / MM-CGI-SF 6 item), (c) and Heartfelt Worry and Felt Isolation (MMCGI 17 items/ MM-CGI-SF 6 item). Items use 5-point Likert scales, ranging from 1 (strongly disagree) to 5 (strongly agree) which produces a range of possible scores of $50-250$ for the MM-CGI, and 18 - 90 for the MM-CGI-SF. For the MM-CGI, subscale A scores range from 18 - 90, subscale B scores range from 15 - 75 and subscale C scores range from 17- 85. For the MM-CGI-SF, all three subscales scores range from 6 - 30. Previous studies have reported acceptable levels of reliability for each subscale and the scale as a whole, with internal consistency estimates ranging from .80 to .98 (Marwit \& Meuser 2001;2002;2005; Liew, 2018).

\section{Zarit Burden Interview Short Form (ZBI-SF)}

The ZBI-SF (Bedard et al., 2001) is a shortened 12-item version of the original 22-item Zarit Burden Interview (Zarit et al., 1980; Zarit, Orr \& Zarit, 1985). This measurement examines burden/strain associated with the caregiving role. The items are rated on a 5-point Frequency scale, ranging from never to nearly always present, which is summed to generate a total score. The scores range from 0 to 48 and scores above 17 are considered as high caregiver burden (Bedard et al, 2001). The short form has been previously shown to correlate strongly with the original 22-item version ( $r=.92-.97$ ) (Bedard et al, 2001). The reliability of the scale in this sample was high (Cronbach's $\alpha=.86$ ).

Caregiver Resilience - Wagnild and Young Resilience Scale Short Version (RS-14)

The RS-14 measures capacity to withstand life stressors, and to thrive and make meaning from challenges (Wagnild \& Young, 1993). It comprises 5 essential characteristics of meaningful life - purpose, perseverance, self-reliance, equanimity and existential aloneness (Wagnild, 2009). The short version has indicated good validity and reliability from several 
studies (Wagnild \& Young, 1993; Wagnild, 2009), and the scale has demonstrated good reliability in this sample (Cronbach's $\alpha=.92)$.

\section{Analytic Strategy}

The analyses were conducted in two linked phases. First, a series of exploratory factor analyses were conducted to determine the optimal number of factors for the full 50 -item and abbreviated 18-item versions of the MM-CGI. Based on previous research (Marwit \& Meuser., 2001; 2002; 2004; Liew et al., 2018) it was predicted that a model with three correlated factors would be the best fitting model. Second, to assess concurrent validity of the MM-CGI/ SF, the best fitting model of the MM-CGI / SF and its subscales, were correlated with two different measures; Zarit Burden Interview Short Form (ZBI-SF; Bedard et al., 2001) and Wagnild and Young Resilience Scale Short Version (RS-14; Wagnild \& Young, 1993), aswell as two caregiving characteristic variables; duration of caregiving and additional support. It was predicted that pre death grief (MM-CGI-/SF) would be positively related to caregiver burden (ZBI-SF) and negatively related to caregiver resilience (RS-14). It was also predicted that predeath grief would be positively related to caregiving duration and negatively related to additional support.

The factor structure of the full and abbreviated scale items was determined using exploratory factor analysis (EFA). The models were estimated using robust maximum likelihood (MLR) using Mplus 8.1 (Muthén, \& Muthén, 2018). Models with two or more factors employed an oblique (Geomin) rotation. Eight models were tested; models included 1 to 4 factors for both the full and abbreviated scale items. The fit of each model was assessed using a number of goodness-of-fit statistics: A non-significant chi-square-test $\left(\chi^{2}\right)$ is indicative of excellent model fit, however, this test is positively related to sample size and therefore a 
significant result should not solely lead to the rejection of a model in large sample-sizes (Tanaka, 1987). Two incremental fit-indices were used to assess goodness of model-fit compared to an independence model: The Comparative Fit Index (CFI) and Tucker-Lewis Index (TLI), both for which values $>.90$ and $>.95$ indicate adequate and excellent fit, respectively (Hu \& Bentler, 1995). The Root Mean Square Error of Approximation (RMSEA) values and Standardized Root Mean Square Residual (SRMR) with values $<.08$ and $<.05$ indicating adequate and excellent model fit, respectively. These indices were supplemented by the Bayesian Information Criterion (BIC) with lower values indicting better model fit:

\section{Results}

The fit statistics for all EFAs are reported in Table 2.

\section{Insert table 2 here}

The fit statistics for the full version of the MM-CGI showed that none of the models adequately fitted the data; although the RMSEA was acceptable for models with 2 or more factors, the TLI and CFI were less than .90 for all models. The RMSEA, TLI, and CFI all indicated that the MM-CGI Short From model with three factors was acceptable in terms of model fit. In addition, the MM-CGI-SF three-factor model was significantly better than the MM-CGI-SF two-factor model $\left(\Delta \chi^{2}=145.34, \Delta \mathrm{df}=16, \mathrm{p}<.05\right)$. The BIC was also lowest for the three-factor model. On this basis, the three-factor model was considered to be the best model.

The factor loadings are reported in Table 3. The 6 items that were designed to measure "Personal Sacrifice and Burden" all loaded strongly and positively on factor 1, and the "Heartfelt Sadness and Longing" all loaded strongly and positively on factor 2. Item number 3, "I will be tied up with this for who knows how long" cross-loaded on factor 2 (Heartfelt 
Sadness and Longing). Factor 3 (Worry and Felt Isolation) was less well defined with 2 items cross loading on factor 2; indeed, the loadings were higher on factor 2 than factor 3 , the factor they were designed to measure. The items were "I spend a lot of time worrying about the bad things to come" and "Dementia is like a double loss. I've lost the closeness with my loved one and connectedness with my family".

\section{Insert table 3 here}

The factor correlations, estimates of reliability (Cronbach's alpha), and the mean sub-scale scores are reported in table 4 . All three factors were positively correlated ranging from .49 to .66. The correlations were not too high as to suggest redundancy. The reliability of the scales was also adequate ranging from .79 to .85 .

\section{Insert table 4 here}

Scale scores based on the MM-CGI-SF three factor model were correlated with duration of caregiving, additional support and two scale measures; caregiver burden (ZBI-SF) and resilience (RS-14). The correlations are reported in Table 5. As predicted, ZBI-SF strongly positively correlated (.46 to .70) and RS-14 negatively correlated (-.11 to -.27) with each of the three MM-CGI-SF subscales. Additional support also negatively correlated (-.11 to -.38) with each MM-CGI-SF factor. Duration of caregiving had significant positive correlations with only Subscale Personal Sacrifice and Burden and Worry and Felt Isolation (.11, .11 respectively). The correlation was not statistically significant for subscale Heartfelt Sadness and Longing ( $p>$ $.05)$. 


\section{Discussion}

The primary aim of this study was to test a series of alternative factor analytical models of the MM-CGI and MM-CGI-SF using a sample of UK-based dementia caregivers. This is also the first study to make use of the MM-CGI / SF scale in a UK population. The large sample size, and contemporary factor analytical approach, allowed us to comprehensively examine the dimensional structure of this scale. On the basis of fit indices reported in Table 2 the MM-CGI-SF three-factor model (Personal Sacrifice and Burden, Heartfelt Sadness and Longing and Worry and Felt Isolation) provided an adequate fit to the data and was considered to be a better than the alternative models. The fit statistics for the full 50-item version of the MM-CGI indicated that none of the models adequately fitted the data. This suggests that MMCGI-SF is a more robust measure than MM-CGI given its better model fit, but clinically more favourable given its shorter length and thus quicker completion time.

The total MM-CGI-SF scale and the three subscales demonstrated adequate levels of internal consistency. All the factor loadings for this model were positive and statistically significant. Correlations between the three factors ranged from .49 to .66 showing the unique predicting validity of each factor. Further, the correlations reported in Table 5 show that the MM-CGI-SF subscales correlated significantly with other related psychological constructs; duration of caregiving, additional support, resilience (RS-14) \& caregiver burden (ZBI-SF) thus demonstrating construct validity. Focusing on the scale measures specifically, ZBI-SF strongly positively correlated with all MM-CGI-SF three subscales (.46 to .70). This further signifies the validity of the MM-CGI-SF, as caregiver burden is a bedrock outcome variable and is the most widely used scale in dementia caregiving literature. RS-14 was significantly negatively correlated with the MM-CGI-SF subscales (-.11 to -.27). This suggests that caregivers with higher grief symptoms scored lower on resilience levels, and thus were more 
vulnerable to experiencing emotions such as existential aloneness, emptiness and a lack of purpose.

Despite the three-factor MM-CGI-SF model showing an adequate model fit, there was an apparent pattern of deviation from the original factor structure proposed by Marwit \& Meuser (2005). All items that were designed to measure Subscale A Personal Sacrifice and Burden, and Subscale B Heartfelt Sadness and Longing, loaded strongly and positively onto their factors. However, Factor 3 Worry and Felt Isolation was less well defined with several items cross loading on factor 2. Two of the items; "I spend a lot of time worrying about the bad things to come" and "Dementia is like a double loss.. I've lost the closeness with my loved on and connectedness with my family", loaded higher in factor 2 than factor 3 . This is a notable finding, as it questions whether items in subscale $\mathrm{C}$ are discrete concepts underlying Worry and Felt Isolation, or whether some of the items reflect more emotions associated with subscale B Heartfelt Sadness and Longing.

The items associated with 'Worry and Felt Isolation' generally loaded well onto Subscale C, (C1, C4, C6) whereas the other three items (C2, C3, C5) appeared slightly less discrete. Items C2 and C5 do appear to reflect the dimension of 'worry' while the two elements of item C3 (reflecting loss of closeness to the 'loved one' and the 'family') may have impacted on how it was interpreted by study participants.

Whilst the two constructs of 'Worry' and 'Felt Isolation' are undoubtedly linked, it is questionable whether they should come under the same subscale dimension. The 'Felt Isolation' component reflects feelings of loneliness from the outside world as well as the loss of emotional connectedness / attachment between the caregiver and the care-recipient due to impaired communication. These feelings of despair and isolation are likely to have a reciprocal effect on the 'worry' items and thus on caregivers thought processes around excessive worry 
and fear about the future and caregiving role. The research literature on grief, outside the context of dementia caregiving, recognises worry and rumination as significant risk factors for complicated grief (Eimsma et al., 2017), thus having detrimental impacts such as sleep disturbance, restlessness, fatigue, irritability and poor concentration. Our finding however question whether worry should be identified as an element intertwined within the pre-death grieving process, or whether it should be seen as separate construct which is measured outside of the MM-CGI-SF.

This finding supports Liew et al (2018) who also revealed a replicable threedimensional MM-CGI-SF structure but suggested that the "worry" and "felt isolation" component of subscale $\mathrm{C}$ are two separate dimensions undermining the grieving process. Given that our results and Liew et al (2018) are the only studies who have factor analysed MM-CGISF, it can be suggested that replication and revision of Subscale C items may be useful before drawing on a final conclusion of the factor structure. A particular temporal issue which may require revision is the shifting present and future focused questions used in Subscale $\mathrm{C}$ and potential variability in how these may be endorsed by a carer when assessed retrospectively or concurrently. Ultimately, researchers will be employing the MM-CGI-SF to examine caregivers who are 'in the process' and 'in different stages of the process' of experiencing AG. Being within this evolving AG process may complicate the carer's future perspective.

Despite these discrepancies, MM-CGI-SF still contains good psychometric properties and thus can be used to assess AG. We do not, at this stage, recommend the removal of the cross-loading items as this would lead to inconsistent norms being produced in different studies, and would preclude direct comparison between scales derived from different numbers of items per subscale. However, the refinement of the scale would be warranted by the original authors if this pattern of cross-loadings was found to be consistent across different samples. 
Importantly, it has shown its ability to detect elements of burden, sadness and isolation in a large sample of UK-based dementia caregivers. Our findings illustrate that a significant number of caregivers experience the multifaceted emotions associated with AG. Eighty-two percent of caregivers in this study reported average or high levels of AG $(64 \% ; 18 \%$ respectively). This is consistent with literature highlighting that $\mathrm{AG}$ is a complex, yet relatively common process in dementia caregivers. It deserves recognition and further attention in the literature and can be used to assess the emotional challenges of this population thus informing clinical practice (Chan et al., 2013; Holm, Arestedt \& Alvariza's, 2019). Ultimately, our findings highlight the need for health care professionals to be mindful of the multifaceted nature of the grief process, which may start long before the death of a loved one, in order to assess the carers needs adequately and thus provide appropriate support. Researchers should use the most robust and psychometrically sound scales to further explore the needs of this population while minimising the demands that are placed upon the caregiver.

While comprehensive assessment of the individual with dementia is routinely offered throughout the world, the emotional needs of the carers receive comparatively less attention within health care services. By having a brief grief scale such as the MM-CGI-SF readily available in routine practice, practitioners can identify caregivers with high AG who may benefit from further grief focused, psychological interventions. Caregivers with high AG may also be missed by other commonly used scales, such as the Caregiver Burden Scale (Liew \& Yap, 2019) and the Caregiver Strain Index (Sullivan, 2002). Such interventions may help caregivers cope with multiple, incremental losses associated with the pre-death grieving process, as well as the coinciding complex emotions involved - which are recognised in the MM-CGI-SF scale. Although grief interventions in the research literature predominately focus on the post-death context, interventions can possibly mirror the dimensions of AG. For example, AG interventions should focus on aspects of 'Personal Sacrifice and Burden' which 
include the practical demands and 'sacrifice' of caring for a loved one, like the giving up of personal hobbies, employment and social life. While practical help such as respite and financial assistance are likely to be a prerequisite to the provision of space for emotional support, focus on the 'Heartfelt Sadness and Longing' that the cruel dementia process causes, is likely to be beneficial in the longer term adaptation to the loss. Focus on new ways to maintain a continual connection and meaningful relationship with the care recipient would be important, while their functional and cognitive abilities continue to change. Although further exploration of the validity of the 'Worry and Felt Isolation' construct is necessary, it would appear valuable that individuals have available to them professional help which assists them in maintaining their social relationships and supports them in planning for the future in a sensitive and timely manner. Holm, Arestedt and Alvariza's (2019) finding that predeath grief in family caregivers was predictive of post-death grief, independent of anxiety and depression symptoms, highlights the value of early detection of AG leading to timely and focused interventions to ease the depth or duration of the grief process.

Several limitations of this study are noteworthy. Firstly, the measures were administered online. It is possible that caregivers with limited computing abilities or lower literacy were underrepresented. Therefore, clinical interviews as well as self-report may have been a superior method of AG assessment. Secondly, the stage of dementia of the carerecipient (i.e. mild, moderate or severe) was not recorded in the study. Research suggests that AG is sensitive to disease severity (Liew et al., 2018); therefore, future research should examine AG at different disease stages. It is clear that the dementia journey and thus AG is not a linear process but is impacted on by the disease stage but also the multitude of practical issues such as living arrangements and the process of transitioning between independent living, supported living, residential care and levels of family support. Further exploration of the impact 
of these circumstances and transitionary processes on AG should be examined to develop understanding of caregiver needs during the caring phase but also the implications for the postdeath grieving process. While the methodology of this study which examined current emotional experiences of participants is preferable to retrospective design, longitudinal research which would tap into the temporal variations in grieving cognitions and emotions would further assist in our understanding of this construct. A comprehensive understanding of the AG process cannot be obtained through quantitative empiricism alone. Caregiving is extremely personal, idiosyncratic and multi-dimensional for every person who provides care. Additional qualitative research examining AG in caregivers will provide an in depth, valuable contribution to the evidence base.

To conclude, this study has supported previous empirical findings that identify three dimensions of AG; Personal Sacrifice and Burden; Heartfelt Sadness and Longing; and Worry and Felt Isolation. Based on a large sample of UK-based dementia caregivers, exploratory factor analysis indicated that a correlated three-factor MM-CGI-SF model was the best fitting model. The MM-CGI-SF demonstrated adequate psychometric properties; however, Subscale C Worry and Felt Isolation should be used with caution in research and clinical practice as it needs further replication and revision to assess its dimensionality. Overall, the MM-CGI-SF is a useful tool, it is psychometrically more robust than the MM-CGI and requires shorter administration time. Its use both clinically and scientifically can help aid in the understanding and articulation of the AG experience. Validation of this scale also opens doors to revision of current dementia caregiving models. Future research should examine the MM-CGI-SF and its relationship with other key measures in order to develop the most comprehensive model of caregiver distress. The utility of the MM-CGI-SF ultimately depends on the larger context of its implementation - we hope this study opens opportunities for AG assessment and intervention to ensure caregivers have access to the best possible emotional support they deserve. 


\section{Conflict of Interests}

We have no conflict of interest to declare.

Funding: No financial support was received for the research, authorship and/or publication of this article.

\section{Acknowledgements}

The authors would like to thank Professor Thomas M. Meuser for providing the original scales, Join Dementia Research, Young Dementia UK \& the participants for taking part in this research. 


\section{References}

Acton, G. J., \& Kang, J. (2001). Interventions to reduce the burden of caregiving for an adult with dementia: A meta-analysis. Research in Nursing \& Health, 24(5), 349-360. doi: 10.1002/nur.1036

Alvelo, J., Cancio-Gonzalez, R. E., \& Collazo, A. (2018). Validation of a Spanish Version of the Marwit-Meuser Caregiver Grief Inventory Short Form in a Puerto Rican Sample. Research on Social Work Practice, 28(4), 507-518. doi: https://doi.org/10.1177/1049731516656801

Alzheimer's Research UK. (2015). Dementia in the family (pp. 1-38). Great Abington, UK: Alzheimer's Research UK. Retrieved from https://www.alzheimersresearchuk.org/wpcontent/uploads/2015/12/ Dementia-in-the-Family-The-impact-on-carers.pdf

Alzheimer's, Association. (2015). 2015 Alzheimer's disease facts and figures. Alzheimer's \& Dementia: The Journal of the Alzheimer's Association, 11(3), 332. doi: 10.1016/j.jalz.2015.02.003

Beck, A. T., Ward, C., Mendelson, M., Mock, J., \& Erbaugh, J. (1961). Beck depression inventory (BDI). Arch Gen Psychiatry, 4(6), 561-571

Bédard, M., Molloy, D. W., Squire, L., Dubois, S., Lever, J. A., \& O'Donnell, M. (2001). The Zarit Burden Interview: a new short version and screening version. The Gerontologist, 41(5), 652-657. doi: https://doi.org/10.1093/geront/41.5.652

Blandin, K., \& Pepin, R. (2017). Dementia grief: A theoretical model of a unique grief experience. Dementia, 16(1), 67-78. doi:10.1177/1471301215581081

Boss, P. (1999). Ambiguous loss: Learning to live with unresolved grief. Cambridge, MA: Harvard University Press. 
Boss, P. (2011). Loving someone who has dementia: How to find hope while coping with stress and grief. New York, NY: Jossey-Bass.

Brodaty, H., \& Donkin, M. (2009). Family caregivers of people with dementia. Dialogues in Clinical Neuroscience, 11(2), 217

Chan, W. C. H., Wong, B., Kwok, T., \& Ho, F. (2017). Assessing grief of family caregivers of people with dementia: validation of the Chinese version of the Marwit-Meuser caregiver grief inventory. Health \& social work, 42(3), 151-158. doi: https://doi.org/10.1093/hsw/hlx022

Cheng, S. T. (2017). Dementia caregiver burden: A research update and critical analysis. Current Psychiatry Reports, 19(9), 64. doi: 10.1007/s11920-017-0818-2

Eisma, M. C., Boelen, P. A., Schut, H. A., \& Stroebe, M. S. (2017). Does worry affect adjustment to bereavement? A longitudinal investigation. Anxiety, Stress, \& Coping, 30(3), 243-252. doi: https://doi.org/10.1080/10615806.2016.1229464

Elvish, R., Lever, S. J., Johnstone, J., Cawley, R., \& Keady, J. (2013). Psychological interventions for carers of people with dementia: A systematic review of quantitative and qualitative evidence. British Association for Counselling and Psychotherapy, 13(2), 106125. doi: https://doi.org/10.1080/14733145.2012.739632

Frank, J. (2008). Evidence for grief as the major barrier faced by Alzheimer caregivers: A qualitative analysis. American Journal of Alzheimer's Disease and Other Dementias, 22, 516-527. doi: 10.1177/1533317507307787.

Holley, C. K., \& Mast, B. T. (2009). The impact of anticipatory grief on caregiver burden in dementia caregivers. The Gerontologist, 49(3), 388-396. doi: https://doi.org/10.1093/geront/gnp061 
Holm, M., Årestedt, K., \& Alvariza, A. (2019). Associations between Predeath and Post-death Grief in Family Caregivers in Palliative Home Care. Journal of Palliative Medicine. doi: https://doi.org/10.1089/jpm.2019.0026

Hu, L.T., \& Bentler, P. M. (1995). Evaluating model fit. In R. H. Hoyle (Ed.), Structural equation modeling: Concepts, issues, and applications (p. 76-99).

Jones, P. S., \& Martinson, I. M. (1992). The experience of bereavement in caregivers of family members with Alzheimer's disease. Image: The Journal of Nursing Scholarship, 24(3), 172-176. doi: https://doi.org/10.1111/j.1547-5069.1992.tb00714.x

Karger, C. R. (2018). Emotional experience in patients with advanced Alzheimer's disease from the perspective of families, professional caregivers, physicians, and scientists. Aging \& Mental Health, 22(3), 316-322. doi: 10.1080/13607863.2016.1261797

Large, S., \& Slinger, R. (2015). Grief in caregivers of persons with Alzheimer's disease and related dementia: A qualitative synthesis. Dementia, 14(2), 164-183. doi: $10.1177 / 1471301213494511$.

Liew, T. M., Yeap, B. I., Koh, G. C. H., Gandhi, M., Tan, K. S., Luo, N., \& Yap, P. (2018). Detecting Predeath grief in family caregivers of persons with dementia: validity and utility of the Marwit-Meuser caregiver grief inventory in a multiethnic Asian population. The Gerontologist, 58(2), e150-e159.Marwit-Meuser caregiver grief inventory in a multi-ethnic Asian population. The Gerontologist, 58(2), e150-e159. doi: https://doi.org/10.1093/geront/gnx097

Liew, T. M., \& Yap, P. (2019). A 3-item screening scale for caregiver burden in dementia caregiving: Scale development and score mapping to the 22-item Zarit Burden Interview. Journal of the American Medical Directors Association, 20(5), 629-633. DOI:https://doi.org/10.1016/j.jamda.2018.11.005 
Lindauer, A., \& Harvath, T. A. (2014). Pre-death grief in the context of dementia caregiving: A concept analysis. Journal of Advanced Nursing, 70(10), 2196-2207. doi:

\section{$10.1111 /$ jan. 12411}

Lord, N. D. (2010). The continued impact of young onset dementia on dependent children as they make the transition into adulthood-a follow up study to Allen, Oyebode and Allen (2009) (Doctoral dissertation, University of Birmingham).

MacCourt, P., McLennan, M., Somers, S., \& Krawczyk, M. (2017). Effectiveness of a grief intervention for caregivers of people with dementia. OMEGA-Journal of Death and Dying, 75(3), 230-247. doi: https://doi.org/10.1177/0030222816652802

Marwit, S. J., \& Meuser, T. M. (2002). Development and initial validation of an inventory to assess grief in caregivers of persons with Alzheimer's disease. The Gerontologist, 42(6), 751-765. doi: https://doi.org/10.1093/geront/42.6.751

Marwit, S. J., \& Meuser, T. M. (2005). Development of a short form inventory to assess grief in caregivers of dementia patients. Death Studies, 29(3), 191-205. doi: https://doi.org/10.1080/07481180590916335

McLennon, S. M., Bakas, T., Habermann, B., \& Meuser, T. M. (2014). Content and face validity of the Marwit-Meuser caregiver grief inventory (short form) in African American caregivers. Death studies, 38(6), 365-373. doi: https://doi.org/10.1080/07481187.2013.766657

Meichsner, F., \& Wilz, G. (2018). Dementia caregivers' coping with pre-death grief: Effects of a CBT-based intervention. Aging \& Mental health, 22(2), 218-225. doi: https://doi.org/10.1080/13607863.2016.1247428

Meichsner, F., Schinköthe, D., \& Wilz, G. (2016). Managing loss and change: grief interventions for dementia caregivers in a CBT-based trial. American Journal of 
Alzheimer's Disease \& Other Dementias, 31(3), 231-240. doi: https://doi.org/10.1177/1533317515602085

Meuser, T. M., \& Marwit, S. J. (2001). A comprehensive, stage-sensitive model of grief in dementia caregiving. The Gerontologist, 41(5), 658-670. doi: https://doi.org/10.1093/geront/41.5.658

Meuser, T. M., Marwit, S., \& Sanders, S. (2004). Assessing grief in family caregivers. Living with grief: Alzheimer's disease, 170-195.

Millenaar, J. K., van Vliet, D., Bakker, C., Vernooij-Dassen, M. J., Koopmans, R. T., Verhey, F. R., \& de Vugt, M. E. (2014). The experiences and needs of children living with a parent with young onset dementia: results from the NeedYD study. International Psychogeriatrics, 26(12), 2001-2010. doi: https://doi.org/10.1017/S1041610213001890

Murray, J. A. (2001). Loss as a universal concept: A review of the literature to identify common aspects of loss in diverse situations. Journal of Loss \&Trauma, 6(3), 219-241. https://doi.org/10.1080/108114401753201679

Muthén, L.K. \& Muthén, B.O. (2018). Mplus User’s Guide. Eighth Edition. Los Angeles, CA: Muthén \& Muthén.

National Collaborating Centre for Mental Health. The Dementia Care Pathway. Full implementation guidance. London: National Collaborating Centre for Mental Health; 2018. Retrieved from: https://www.rcpsych.ac.uk/docs/default-source/improvingcare/nccmh/nccmh-dementia-care-pathway-full-implementationguidance.pdf?sfvrsn=cdef189d_6

NICE guideline. (2018, June 20). Dementia: assessment, management and support for people living with dementia and their carers. Retrieved from https://www.nice.org.uk/guidance/ng97/chapter/Recommendations\#supporting-carers 
Pearlin, L. I., Mullan, J. T., Semple, S. J., \& Skaff, M. M. (1990). Caregiving and the stress process: An overview of concepts and their measures. The Gerontologist, 30(5), 583-594. doi: $10.1093 /$ geront/30.5.583

Pinquart, M., \& Sörensen, S. (2003). Differences between caregivers and noncaregivers in psychological health and physical health: a meta-analysis. Psychology and Aging, 18(2), 250. doi: http://dx.doi.org/10.1037/0882-7974.18.2.250

Rando, T. (2000). Clinical dimensions of anticipatory mourning. Chicago, IL: Research Press.

Rando, T. A. (1986). A comprehensive analysis of anticipatory grief: Perspectives, processes, promises, and problems. In T. Rando (Ed.), Loss and anticipatory grief (pp. 1-36). New York: Lexington Books.

Rando, T. A. (2000). Anticipatory mourning: A review and critique of the literature. In T. Rando (Ed.), Clinical dimensions of anticipatory mourning: Theory and practice in working with the dying, their loved ones, and their caregivers (pp. 17-50). Champaign, IL: Research Press.

Sullivan, M. T. (2002). Caregiver strain index (CSI). Journal of Gerontological Nursing, 28(8), 4-5. DOI: 10.1097/00004045-200303000-00024

Tanaka, J. (1987). How big is enough Sample size and goodness-of-fit in structural equation models with latent variables? Child Development, 58, 134-146. 
Table 1. Scale Scores and Demographic information of the Caregivers and Care Recipients.

\begin{tabular}{|c|c|}
\hline Characteristic & Caregivers \\
\hline Age Mean (SD) & 54 years $(12.9)$ \\
\hline Age range & $18-85$ years \\
\hline \multicolumn{2}{|l|}{ Gender, $n(\%)$} \\
\hline Female & $440(86.6 \%)$ \\
\hline Male & $67(13.2 \%)$ \\
\hline Prefer not to say & $1(.2 \%)$ \\
\hline \multicolumn{2}{|l|}{ Ethnicity, $n(\%)$} \\
\hline White/White British & $490(96.5 \%)$ \\
\hline Other ${ }^{a}$ & $17(3.5 \%)$ \\
\hline \multicolumn{2}{|l|}{ Relationship to care recipient, $n(\%)$} \\
\hline Parent & $252(49.9)$ \\
\hline Spouse/Partner & $120(23.7 \%)$ \\
\hline Other ${ }^{b}$ & $134(26.44 \%)$ \\
\hline \multicolumn{2}{|l|}{ Duration of caregiving (years) $n(\%)$} \\
\hline$<1$ year & $37(7.3 \%)$ \\
\hline $1-3$ years & $213(41.9 \%)$ \\
\hline 4-6 years & $147(28.9 \%)$ \\
\hline $7+$ years & $108(21.3 \%)$ \\
\hline \multicolumn{2}{|l|}{ Frequency of caregiving $n(\%)$} \\
\hline Full time & $179(35.2 \%)$ \\
\hline $5+$ hours a day & $66(13.0 \%)$ \\
\hline 1-4 hours a day & $86(16.9 \%)$ \\
\hline A few times a week & $141(27.8 \%)$ \\
\hline Once a week & $31(6.1 \%)$ \\
\hline \multicolumn{2}{|l|}{ Additional Support $n(\%)$} \\
\hline None & $77(15.2 \%)$ \\
\hline Very little support & $132(26.0 \%)$ \\
\hline Limited support & $128(25.2 \%)$ \\
\hline Good support & $99(19.5 \%)$ \\
\hline Excellent support & $67(13.2 \%)$ \\
\hline MM-CGI score, mean (SD) & $161.08(36.70)$ \\
\hline MM-CGI-SF score, mean (SD) & $58.43(14.34)$ \\
\hline ZBI-SF score, mean (SD) & $36.80(9.02)$ \\
\hline RS-14 score, mean $(S D)$ & $74.24(13.92)$ \\
\hline \multicolumn{2}{|l|}{ Care Recipient Information } \\
\hline \multicolumn{2}{|l|}{ Care Recipients living situation, $n(\%)$} \\
\hline IL to supported accommodation & $94(21.9 \%)$ \\
\hline $\begin{array}{l}\text { Living with family to supported } \\
\text { accommodation }\end{array}$ & $42(9.8 \%)$ \\
\hline
\end{tabular}


Supported accommodation to living with family

$8(1.9 \%)$

IL to living with family and/or receiving home care

$285(66.4 \%)$

Notes: IL = Independent living.

a Participants categorized as "other" consisted of prefer not to say, other, black/black Asian, Asian/Asian British and mixed. ${ }^{\mathrm{b}}$ Participants categorized as "other" consisted of siblings, sons, daughters, friends/neighbour, other relatives, and other. 
Table 2. Fit Statistics for Alternative Factor Analytic Models of MM-CGI \& MM-CGI-SF Items.

\begin{tabular}{|c|c|c|c|c|c|c|c|c|c|c|}
\hline Factors & $\chi^{2}$ & $\mathrm{df}$ & $\bar{p}$ & $\Delta \chi^{2}$ & $\Delta \mathrm{df}$ & $\bar{p}$ & CFI & $\overline{T L I}$ & RMSEA & $\mathrm{BIC}$ \\
\hline \multicolumn{11}{|c|}{ MM-CGI } \\
\hline 1 & $4891.664 *$ & 1175 & .000 & & & & .630 & .614 & $.087(.085-.090)$ & 61799.840 \\
\hline 2 & $3641.997 *$ & 1126 & .000 & 965.512 & 49 & .000 & .750 & .728 & $.073(.071-.076)$ & 60655.494 \\
\hline 3 & $2845.298 *$ & 1078 & .000 & 739.863 & 48 & .000 & .824 & .800 & $.063(.060-.066)$ & 60066.970 \\
\hline 4 & $2475.276^{*}$ & 1031 & 0.000 & 299.252 & 47 & .000 & .856 & .829 & $.058(.055-.061)$ & 59903.872 \\
\hline \multicolumn{11}{|c|}{ MM-CGI-SF } \\
\hline 1 & $996.032 *$ & 135 & .000 & & & & .688 & .646 & $.124(.117-.131)$ & 22758.151 \\
\hline 2 & $473.556^{*}$ & 118 & .000 & 448.812 & 17 & .000 & .871 & .833 & $.085(.077-.093)$ & 22254.132 \\
\hline 3 & $299.890^{*}$ & 102 & .000 & 145.341 & 16 & .000 & .928 & .892 & $.068(.059-.077)$ & 22144.547 \\
\hline 4 & 2910.009 & 87 & .000 & 86.417 & 15 & .000 & .953 & .918 & $.060(.050-.070)$ & 22148.838 \\
\hline
\end{tabular}


Table 3. Standardised Factor Loadings for MM-CGI-SF Three-Factor Model.

Note: Only statistically significant $(\mathrm{p}<.05)$ loadings are reported.

\begin{tabular}{|c|c|c|c|}
\hline $\begin{array}{l}\text { Item: } \\
\text { During the past } 4 \text { weeks... }\end{array}$ & Factor 1 & Factor 2 & Factor 3 \\
\hline A1. I've had to give up a great deal to be a caregiver. & .620 & .174 & \\
\hline A2. I feel I am losing my freedom. & .702 & .232 & \\
\hline A3. I will be tied up with this for who knows how long. & .438 & .326 & \\
\hline $\begin{array}{l}\text { A4. Independence is what I've lost. I don't have the freedom } \\
\text { to go and do what I want. }\end{array}$ & .821 & & \\
\hline $\begin{array}{l}\text { A5. I wish I had an hour to myself each day to pursue } \\
\text { personal interests. }\end{array}$ & .524 & & .298 \\
\hline $\begin{array}{l}\text { A6. I'm stuck in this caregiving world and there's nothing I } \\
\text { can do about it. }\end{array}$ & .491 & & \\
\hline $\begin{array}{l}\text { B1. I have this empty, sick feeling knowing that my loved on } \\
\text { is "gone". }\end{array}$ & & .896 & \\
\hline B2. I long for what was, what we had and shared in the past. & & .778 & \\
\hline $\begin{array}{l}\text { B3. I could deal with other serious disabilities better than with } \\
\text { this. }\end{array}$ & & .483 & \\
\hline $\begin{array}{l}\text { B4. It hurts to put her/him to bed at night and realize that } \\
\text { she/he is "gone". }\end{array}$ & & .751 & \\
\hline B5. I feel very sad about what this disease has done. & & .715 & \\
\hline $\begin{array}{l}\text { B6. I've lost other people close to me, but the losses I'm } \\
\text { experiencing now are much more troubling. }\end{array}$ & & .540 & \\
\hline C1. I have nobody to communicate with. & & & .553 \\
\hline $\begin{array}{l}\text { C2. I spend a lot of time worrying about the bad things to } \\
\text { come. }\end{array}$ & -.186 & .573 & .326 \\
\hline $\begin{array}{l}\text { C3. Dementia is like a double loss.. I've lost the closeness } \\
\text { with my loved one and connectedness with my family. }\end{array}$ & & .607 & .173 \\
\hline $\begin{array}{l}\text { C4. My friends simply don't understand what I'm going } \\
\text { through. }\end{array}$ & & & .543 \\
\hline $\begin{array}{l}\text { C5. I lay awake most nights worrying about what's happening } \\
\text { and how I'll manage tomorrow. }\end{array}$ & & .278 & .525 \\
\hline $\begin{array}{l}\text { C6. The people closest to me do not understand what I'm } \\
\text { going through. }\end{array}$ & & & .669 \\
\hline
\end{tabular}


Table 4. Factor correlations, Cronbach's alpha and mean scores for the three-factor model of MM-CGI-SF Items

\begin{tabular}{lccc}
\hline & $\begin{array}{c}\text { Personal } \\
\text { Sacrifice \& } \\
\text { Burden }\end{array}$ & $\begin{array}{c}\text { Heartfelt Sadness } \\
\text { \& longing }\end{array}$ & $\begin{array}{c}\text { Worry \& Felt } \\
\text { Isolation }\end{array}$ \\
\hline Personal Sacrifice \& Burden & 1.00 & & \\
Heartfelt Sadness \& Longing & $.49^{* *}$ & 1.00 & 1.00 \\
Worry \& Felt Isolation & $.55^{* *}$ & $.66^{* *}$ & $17.26(5.40)$ \\
$\begin{array}{l}\text { Scale mean (SD) } \\
\text { Cronbach's alpha }\end{array}$ & $20.49(5.73)$ & $20.39(5.87)$ & .80 \\
\hline
\end{tabular}

** Correlation is significant at the 0.01 level (2-tailed) 
Table 5. MM-CGI subscale correlations with ZBIE, RMBC-Frequency, RMBC-Reaction, Resilience \& Additional Support.

\begin{tabular}{|c|c|c|c|c|}
\hline & $\begin{array}{c}\text { Duration of } \\
\text { caregiving (years) }\end{array}$ & Additional Support & ZBI-SF & Resilience \\
\hline Personal Sacrifice \& Burden & $.11 *$ & $-.38 * *$ & $.70^{* *}$ & $-.14 * *$ \\
\hline Heartfelt Sadness \& longing & .09 & $-.11 * *$ & $.46^{* *}$ & $-.11 * *$ \\
\hline Worry \& Felt Isolation & $.11 *$ & $-.32 * *$ & $.61 * *$ & $-.27 * *$ \\
\hline
\end{tabular}

** Correlation is significant at the 0.01 level (2-tailed).

* Correlation is significant at the 0.05 level (2-tailed). 